\title{
A NEW STABILITY-INDICATING RP-HPLC METHOD FOR DETERMINATION OF CURCUMIN: AN APPLICATION TO NANOPARTICULATE FORMULATION
}

\author{
SUCHITRA PANIGRAHI ${ }^{1}$, RAJASHREE HIRLEKAR ${ }^{* 2}$ \\ ${ }^{1,2}$ Department of Quality Assurance, Vivekanand Education Society's College of Pharmacy, Hashu Advani Memorial Complex, Behind \\ Collector Colony, Chembur(E), Mumbai 400074. Maharashtra, India
}

Email: rajashree.hirlekar@ves.ac.in

Received: 03 Aug 2016 Revised and Accepted: 14 Oct 2016

\begin{abstract}
Objective: The present study was aimed to develop a rapid, accurate, linear, sensitive and stability-indicating high performance liquid chromatographic method for determination of curcumin and to implement the developed method for the estimation of curcumin in the nanoparticulate formulation.

Methods: Method development was performed using various solvent, buffer-solvent ratios, at different flow rates for better resolution and to decrease the run time. The developed method was validated in accordance with the international conference on harmonization (ICH) guidelines. The developed method was implemented to estimate the amount of curcumin in the curcumin-nanoparticulate formulation

Results: The optimum chromatographic conditions with adequate resolution for curcumin (16.10 min) was achieved when the separation was carried using $\mathrm{C}_{18}$ column at ambient temperature with an isocratic elution mode of mobile phase composed of a degassed mixture of phosphate buffer pH 3 and acetonitrile $(50: 50 \mathrm{v} / \mathrm{v})$ at $1.0 \mathrm{ml} / \mathrm{min}$ flow rate with a total run time of $20 \mathrm{~min}$. The developed method was validated for system suitability, accuracy, precision, limit of detection (LOD), limit of quantitation (LOQ), linearity and range. The LOD and LOQ were found to be $0.018 \mathrm{and} 0.056 \mu \mathrm{g} / \mathrm{ml}$ respectively, which indicates that the method was sensitive, and can detect and quantify at lower levels of curcumin. Linearity range was from 5-15 $\mu \mathrm{g} / \mathrm{ml}$ for curcumin with regression coefficient 0.997 indicates that at this concentration range curcumin was highly linear. Percent assay of curcumin was found to be $98.7 \%$ and curcumin recovered was found to be $0.78 \mathrm{mg}$ which are estimated by using the developed method.
\end{abstract}

Conclusion: The developed analytical method is simple, precise, and reproducible and thus can be used for stability-indicating analysis of curcumin in pharmaceutical formulations.

Keywords: Analytical method development, Curcumin, Nanoparticles, RP-HPLC-PDA, Stability-indicating

(C) 2016 The Authors. Published by Innovare Academic Sciences Pvt Ltd. This is an open access article under the CC BY license (http://creativecommons.org/licenses/by/4. 0/) DOI: http://dx.doi.org/10.22159/ijpps.2016v8i12.14473

\section{INTRODUCTION}

Curcumin is a hydrophobic polyphenolic substance isolated from the rhizomes of Curcuma longa Linn. Family (Zingiberaceae) along with other two de-methoxy compounds which are desmethoxycurcumin and bisdemethoxycurcumin. Structurally, curcumin is 1,7-bis (4hydroxy-3-methoxyphenyl)-1,6-heptadiene-3,5-dione (fig. 1). Mostly, it is available in the market as a mixture of three different constituents, commonly known as curcuminoids $[1,2,3]$. It is a coloring principle in turmeric and has been found to have a wide range of pharmacological activities and exhibits significant therapeutic potential in the treatment of wound healing [4], cancer [5], arthritis, atherosclerosis, diabetes mellitus, fever, gastric ulcer, inflammatory bowel disease, lung diseases, malaria, multiple sclerosis, myocardial infarction, osteoporosis, pancreatitis, psoriasis [6]. Safety of curcumin at very high doses has been proved in various animal and human studies. These studies led to the approval of curcumin as a 'Generally Regarded as Safe (GRAS)' ingredient by the Food and Drug Administration (FDA) of the United States of America, by the Natural health products directorate of Canada and the Expert Joint Committee of the Food and Agriculture Organization/ World Health Organization (FAO/WHO) on food additives (JECFA) [7].<smiles>COc1cc(/C=C/C(=O)CC(=O)/C=C/c2ccc(O)c(OC)c2)ccc1O</smiles>

Fig. 1: Chemical structure of curcumin
A survey of the literature showed that various analytical techniques are available for determination of curcumin from bulk drug and pharmaceutical dosage forms. A high-performance thin layer chromatography (HPTLC) method has been used for the determination of curcumin in bulk drug and pharmaceutical formulations [8]. Also, capillary electrophoresis methods have been reported for determination and detection of curcumin [9].

Different HPLC methods have been reported for the analysis of curcumin, such as HPLC methods with fluorescence detector have been used for its quantification in biological samples [10]. HPLC-UV methods were also used for the quantitative determination of curcumin in biological samples [11]. HPLC-PDA methods were also reported for determination of curcumin [12] and simultaneous estimation of piperine and curcumin in nanoparticulate formulation [13]. A stability-indicating HPLC method for quantitative determination of curcumin in laboratory samples [14] and simultaneous estimation of silymarin and curcumin also have been reported [1]. Several other methods such as fluorimetric methods [15] and NMR methods [16] have been used for the determination and rapid quantitation of curcumin.

The reported methods were not cost effective due to the use of highly sophisticated detectors, costly solvents such as tetrahydrofuran and some methods were found to be less sensitive. So in the present work a simple, precise, sensitive and stability-indicating method was developed by using low-cost solvent acetonitrile with buffer in ratio $50: 50$, detected by using photodiode array detector which was highly sensitive to detect at a lower concentration. The developed method was used for estimation of curcumin from curcumin nanoparticles in which mobile phase was used for extraction of curcumin. The use of mobile phase as an extracting solvent makes it more compatible with the developed method. 


\section{MATERIALS AND METHODS}

\section{Chemicals and reagents}

Curcumin was kindly supplied by VAV life sciences Pvt. Ltd. (Mumbai, India). Methanol and acetonitrile used were of HPLC grade and were obtained from LOBA-Chemie. Purified water used was of HPLC grade, obtained from JK Labs (Mumbai, India). Other reagents were of analytical grade including potassium dihydrogen orthophosphate, orthophosphoric acid, sodium hydroxide $(\mathrm{NaOH})$, hydrochloric acid $(\mathrm{HCl})$ and hydrogen peroxide obtained from LOBA-Chemie.

Nanoparticulate formulation: Curcumin nanoparticulate formulation labeled to contain $8 \mathrm{mg}$ curcumin per $10 \mathrm{ml}$ of the formulation was prepared by modified hot melt emulsification method [17] at Vivekanand Education Society's College of pharmacy (Chembur, Mumbai).

\section{Instrument}

Analyses were carried out using a Jasco HPLC-MD2010-PDA (MD, USA) system equipped with the pump, rheodyne injector, mixer and photodiode array (PDA) detector. The generated analytical signals were monitored and integrated using chrompass data software. The chromatographic separation was performed using C18 column (reversed phase, $250 \mathrm{~mm} \times 4.6 \mathrm{~mm}$ with 5 micron particle size, enable).

\section{Methods}

\section{Chromatographic conditions}

The method development for analysis of curcumin was performed using (a) various solvent [i.e. acetonitrile and methanol], (b) various buffer-solvent ratio [i.e. solvent A (acetonitrile) and solvent B (Phosphate buffer $\mathrm{pH}$ 3) at the ratio of 70:30, 60:40, 55:45, 50:50 and 45:55], (c) various flow rate [i.e. $0.8,1.0$ and $1.2 \mathrm{ml} / \mathrm{min}$ ] were tried. The injection volume used was $20 \mu \mathrm{l}$ and the analyte was analyzed at $422 \mathrm{~nm}$ wavelength.

\section{Preparation of solutions}

\section{Preparation of buffer solution pH 3.0}

Solution-A (20 mmol): $0.278 \mathrm{gm}$ of potassium dihydrogen orthophosphate monohydrate was weighed and mixed with $100 \mathrm{ml}$ of distilled water.

Solution-B (100 mmol): $1.1 \mathrm{ml}$ of orthophosphoric acid was added in $100 \mathrm{ml}$ distilled water. $94.5 \mathrm{ml}$ of solution-A was mixed with 5.5 $\mathrm{ml}$ of solution- $\mathrm{B}$ and $\mathrm{pH}$ was checked. $\mathrm{pH}$ of the solution was adjusted with $0.5 \mathrm{~N} \mathrm{NaOH}$ if required. This buffer solution was then filtered through $0.45 \mu$ nylon membrane and degassed.

\section{Preparation of diluent}

Mobile phase (pH-3 buffer and acetonitrile in the ratio of 50:50\% $\mathrm{v} / \mathrm{v}$ ) was used as a diluent solution.

\section{Preparation of standard stock solution $(1000 \mu \mathrm{g} / \mathrm{ml})$}

$25 \mathrm{mg}$ of drug curcumin was weighed and transferred into $25 \mathrm{ml}$ volumetric flask. $20 \mathrm{ml}$ of methanol was added, sonicated to dissolve, and then cooled. Volume was made with methanol and mixed to obtain a standard stock solution of $1000 \mu \mathrm{g} / \mathrm{ml}$.

\section{Preparation of working standard solution $(10 \mu \mathrm{g} / \mathrm{ml})$}

From standard stock solution, $1 \mathrm{ml}$ was pipetted out and transferred into $10 \mathrm{ml}$ volumetric flask. Volume was made up to $10 \mathrm{ml}$ with methanol and mixed to obtain a solution of $100 \mu \mathrm{g} / \mathrm{ml}$. From this solution, $1 \mathrm{ml}$ was pipetted out and diluted up to $10 \mathrm{ml}$ with diluent to obtain working standard solution of $10 \mu \mathrm{g} / \mathrm{ml}$. The working standard solution was then injected into HPLC system under the optimized condition and chromatogram was recorded.

\section{Validation of the developed method}

The optimized analytical method was validated for system suitability, linearity and range, precision, limit of detection (LOD), limit of quantitation (LOQ) and accuracy in accordance with ICH guideline for analytical procedures Q2(R1) [18].

\section{System suitability}

System suitability parameters were studied to verify the system performance. Six replicate samples containing curcumin $(10 \mu \mathrm{g} / \mathrm{ml})$ were analyzed using the developed method. Factors such as theoretical plate count, tailing factor, percent relative standard deviation (\% RSD) of peak area and retention time were taken into consideration for testing system suitability.

\section{Linearity and range}

The linearity was evaluated at five concentration levels in the range between $5-15 \mu \mathrm{g} / \mathrm{ml}$ for curcumin. Calibration curve was plotted by plotting concentration against its corresponding peak area and linearity was determined using least square regression analysis. The analytical range was established by the highest and lowest concentrations of analyte where acceptable linearity was obtained.

\section{Precision}

The precision of the developed analytical method carried out at three different concentrations i.e. 5, 10 and $15 \mu \mathrm{g} / \mathrm{ml}$ of curcumin. At each concentration level, six determinations were performed, both intraday and interday variation were expressed in terms of \% RSD.

\section{LOD and LOQ}

Limit of detection (LOD) and quantitation (LOQ) of the developed analytical method was estimated by using the standard deviation of the response and the slope method. The LOD and LOQ were calculated by using the following formula:

$$
\begin{aligned}
& \mathrm{LOD}=\frac{3.3 \times \mathrm{SD}}{\mathrm{S}} \\
& \mathrm{LOQ}=\frac{10 \times \mathrm{SD}}{\mathrm{S}}
\end{aligned}
$$

\section{Accuracy}

The accuracy of the developed analytical method was determined by calculating recovery of the analyte of interest. Standard stock solution $(100 \mu \mathrm{g} / \mathrm{ml})$ of curcumin was spiked into $5 \mathrm{ml}$ placebo of curcumin nanoparticulate formulation at three different levels i.e. $50 \%, 100 \%$ and $150 \%$ of working level concentration $(10 \mu \mathrm{g} / \mathrm{ml})$ i.e. 5,10 , and $15 \mu \mathrm{g} / \mathrm{ml}$. Each level of accuracy sample was injected in triplicate and percent recovery was taken into consideration for testing accuracy. Application of validated method for assay of curcumin
nanoparticulate formulation

Sample preparation- $1 \mathrm{ml}$ of curcumin nanoparticulate formulation $(0.8 \mathrm{mg} / \mathrm{ml})$ transferred into $10 \mathrm{ml}$ of volumetric flask. $7 \mathrm{ml}$ of methanol was added and sonicated for $60 \mathrm{~min}$ for complete extraction The sonicated solution was cooled down to room temperature and volume was made up with methanol, mixed and filtered through $0.45 \mu$ nylon syringe filter to obtain a solution of $80 \mu \mathrm{g} / \mathrm{ml}$. From $80 \mu \mathrm{g} / \mathrm{ml}$ solution, $1 \mathrm{ml}$ was pipetted out and transferred to a $10 \mathrm{ml}$ volumetric flask. Volume was made up with diluents to get a final concentration of $10 \mu \mathrm{g} / \mathrm{ml}$. twenty microliters of standard solutions were injected into HPLC system; chromatogram was recorded and percent assay or recovery was calculated.

\section{Forced degradation study}

\section{Acid hydrolysis}

A volume of $5 \mathrm{ml}$ of stock curcumin solution $(1000 \mu \mathrm{g} / \mathrm{ml})$ for forced degradation was mixed with $5 \mathrm{ml}$ of $0.1 \mathrm{~N}$ hydrochloric acid into round bottom flask (RBF), refluxed at $80{ }^{\circ} \mathrm{C}$ for $4 \mathrm{~h}$ and cooled. Then the solution was transferred into $25 \mathrm{ml}$ volumetric flask and neutralized with $5 \mathrm{ml}$ of $0.1 \mathrm{~N}$ sodium hydroxide. Volume was made up to $25 \mathrm{ml}$ with methanol to obtain a solution of $200 \mu \mathrm{g} / \mathrm{ml}$. The resultant solution was further diluted with diluent to obtain a final solution of $10 \mu \mathrm{g} / \mathrm{ml}$. The final solution was filtered and injected into the HPLC system, and chromatogram was recorded.

\section{Base hydrolysis}

A volume of $5 \mathrm{ml}$ of stock curcumin solution $(1000 \mu \mathrm{g} / \mathrm{ml})$ for forced degradation was mixed with $5 \mathrm{ml}$ of $0.1 \mathrm{~N}$ sodium hydroxide into 25 
$\mathrm{ml}$ volumetric flask and kept at room temperature for $30 \mathrm{~min}$. After $30 \mathrm{~min}$, the solution was needed for neutralization with $5 \mathrm{ml}$ of $0.1 \mathrm{~N}$ hydrochloric acid. Volume was made up to $25 \mathrm{ml}$ with methanol to obtain a solution of $200 \mu \mathrm{g} / \mathrm{ml}$. The resultant solution was further diluted with diluent to obtain the final solution of $10 \mu \mathrm{g} / \mathrm{ml}$. The final solution was filtered and injected into the HPLC system, and chromatogram was recorded.

\section{Neutral hydrolysis}

A volume of $5 \mathrm{ml}$ of stock curcumin solution $(1000 \mu \mathrm{g} / \mathrm{ml})$ for forced degradation was mixed with $5 \mathrm{ml}$ of HPLC grade water into around bottom flask (RBF), refluxed at $80{ }^{\circ} \mathrm{C}$ for $4 \mathrm{~h}$ and cooled. Then the solution was transferred into a $25 \mathrm{ml}$ volumetric flask and volume was made up to $25 \mathrm{ml}$ with methanol to obtain a solution of 200 $\mu \mathrm{g} / \mathrm{ml}$. The resultant solution was further diluted with diluent to obtain the final solution of $10 \mu \mathrm{g} / \mathrm{ml}$. The final solution was filtered and injected into the HPLC system and chromatogram was recorded.

\section{Oxidative degradation}

A volume of $5 \mathrm{ml}$ of stock curcumin solution $(1000 \mu \mathrm{g} / \mathrm{ml})$ for forced degradation was mixed with $5 \mathrm{ml}$ of $6 \%$ hydrogen peroxide into around bottom flask (RBF), refluxed at $80{ }^{\circ} \mathrm{C}$ for $4 \mathrm{~h}$ and cooled. Then the solution was transferred into a $25 \mathrm{ml}$ volumetric flask and volume was made up to $25 \mathrm{ml}$ with methanol to obtain a solution of $200 \mu \mathrm{g} / \mathrm{ml}$. The resultant solution was further diluted with diluent to obtain the final solution of $10 \mu \mathrm{g} / \mathrm{ml}$. The final solution was filtered and injected into the HPLC system and chromatogram was recorded.

\section{Thermal degradation}

A volume of $5 \mathrm{ml}$ of stock curcumin solution $(1000 \mu \mathrm{g} / \mathrm{ml})$ for forced degradation was mixed with $5 \mathrm{ml}$ of methanol into a $25 \mathrm{ml}$ volumetric flask, heated in a hot air oven at $110{ }^{\circ} \mathrm{C}$ for $8 \mathrm{~h}$ and cooled. Then the solution was transferred into a $25 \mathrm{ml}$ volumetric flask and volume was made up to $25 \mathrm{ml}$ with methanol to obtain a solution of $200 \mu \mathrm{g} / \mathrm{ml}$. The resultant solution was further diluted with diluent to obtain the final solution of $10 \mu \mathrm{g} / \mathrm{ml}$. The final solution was filtered and injected into the HPLC system and chromatogram was recorded.

\section{Photolytic degradation}

A volume of $5 \mathrm{ml}$ of stock curcumin solution $(1000 \mu \mathrm{g} / \mathrm{ml})$ for forced degradation was mixed with $5 \mathrm{ml}$ of methanol into a $25 \mathrm{ml}$ volumetric flask, kept in sunlight for $8 \mathrm{~h}$ and cooled. Then the solution was transferred into a $25 \mathrm{ml}$ volumetric flask and volume was made up to $25 \mathrm{ml}$ with methanol to obtain a solution of 200 $\mu \mathrm{g} / \mathrm{ml}$. The resultant solution was further diluted with diluent to obtain the final solution of $10 \mu \mathrm{g} / \mathrm{ml}$. The final solution was filtered and injected into the HPLC system and chromatogram was recorded. Percent degradation was calculated for each condition by using the following formula given below.

$$
\begin{aligned}
& \% \text { Degradation } \\
& =\frac{\text { Area of standard peak-Area of sample peak }}{\text { Area of standard peak }}
\end{aligned} \times 100
$$

\section{RESULTS AND DISCUSSION}

\section{Method development}

The optimum wavelength selected for the estimation of curcumin was $422 \mathrm{~nm}$, based on the maximum absorption using a UV-Visible spectrophotometer. Curcumin is non-ionized hydrophobic with $\mathrm{pKa}$ values 7.8, 8.5 and 9. Initially, methanol and water were tried in various ratios for curcumin but, it was unable to show three separate peaks. Then methanol was replaced by acetonitrile and used in various ratios which showed three peaks for curcumin and its two de-methoxy compounds but peaks were not resolved. To get an optimum resolution between curcumin and its de-methoxy compounds, phosphate buffer was used which has the buffering capacity at three different pKa 2.12, 7.2 and 12.67. At acidic pH, curcumin undergoes ionization and elute out easily from reversed phase column. We have tried various solvent-buffer ratios $(70: 30$, $60: 40,55: 45,50: 50$ and 45:55). However, a combination of acetonitrile and phosphate buffer $\mathrm{pH} 3$ at $50: 50 \mathrm{v} / \mathrm{v}$ has shown good resolution for curcumin at $16.10 \mathrm{~min}$ (Fig.2) but, further increase and decrease in the ratio of the buffer has shown less resolved peaks. Initially, $1.0 \mathrm{ml} / \mathrm{min}$ flow rate was tried, but further increase or decrease in flow rate has not shown adequate separation between curcumin and its two de-methoxy compounds. The optimum chromatographic condition with adequate resolution for curcumin was achieved when the separation was carried using enable $\mathrm{C}_{18}$ column $(250 \mathrm{~mm} \times 4.6 \mathrm{~mm}, 5 \mu)$ at ambient temperature with an isocratic elution mode of mobile phase composed of a degassed mixture of acetonitrile: phosphate buffer $\mathrm{pH} 3(50: 50 \mathrm{v} / \mathrm{v})$ at 1.0 $\mathrm{ml} / \mathrm{min}$ flow rate with a total run time of $20 \mathrm{~min}$. The other methods used tetrahydrofuran as part of mobile phase [9], sophisticated detector $[6,12,13]$, long run time $[10,12]$ which increased the cost of the method of analysis.

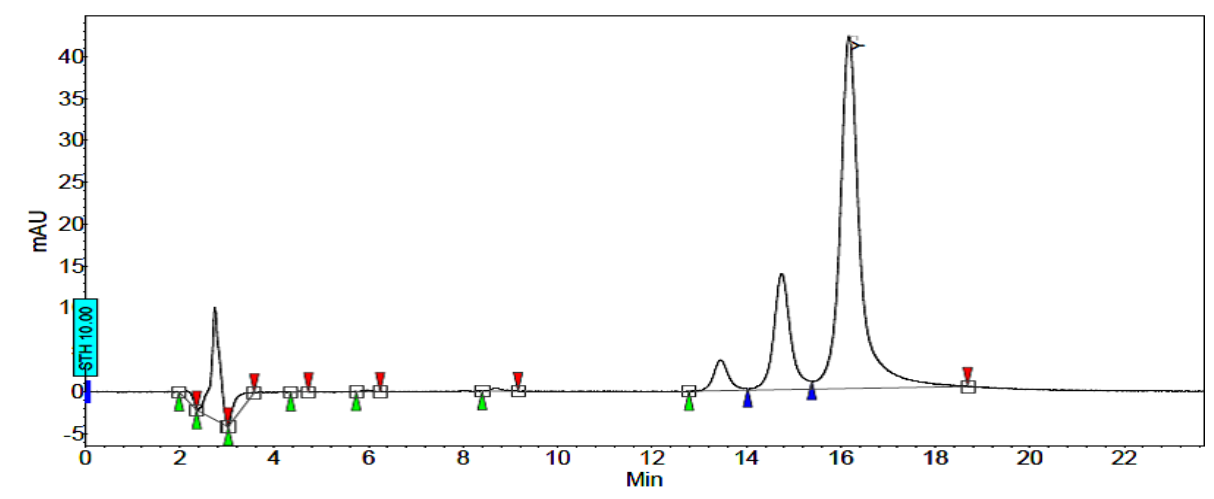

Fig. 2: Chromatogram of curcumin (Y) using optimum chromatographic conditions

\section{Method validation}

\section{System suitability}

The developed method has produced theoretical plate above 2000 for curcumin with tailing factor less than 1.5. Similarly, the \%RSD of peak area and retention time of curcumin was less than 2, which ensures the suitability of the developed method. The results of system suitability study are summarized in table 1.

\section{Acceptance criteria}

1. The relative standard deviation of six replicate injections for peak area and retention time should not be more than $2.0 \%$.

2. The tailing factor should not be more than 2 .

3. The theoretical plates should not be less than 2000 . 
Table 1: System suitability of the developed method

\begin{tabular}{lllll}
\hline Sample & Retention time (min) & Peak area (mAU*sec) & USP tailing factor & USP theoretical plates \\
\hline 1 & 16.10 & 1176.2 & 1.33 & 9815.73 \\
2 & 16.05 & 1141.9 & 1.38 & 9659.33 \\
3 & 16.13 & 1192 & 1.38 & 9751.04 \\
4 & 16.14 & 1173 & 1.36 & 10075.52 \\
5 & 16.11 & 1166 & 1.33 & 10046.80 \\
6 & 16.09 & 1150 & 1.34 & 9961.03 \\
Mean & 16.103 & 1166.76 & 1.353 & 9884.90 \\
\%RSD & 0.14 & 1.55 & 1.72 & 1.70 \\
\hline
\end{tabular}

\section{Linearity and range}

The correlation coefficient $\left(\mathrm{R}^{2}\right)$ of curcumin was found to be 0.997 , which confirms its linearity in the range of $5-15 \mu \mathrm{g} / \mathrm{ml}$. The results of linearity are summarized in table 2 .

Acceptance criteria: The correlation coefficient $\left(\mathrm{R}^{2}\right)$ value should not be less than 0.995 over the working range.

Table 2: Linearity and range of the developed method

\begin{tabular}{ll}
\hline Parameter & Results of curcumin \\
\hline correlation coefficient $\left(\mathrm{R}^{2}\right)$ & 0.997 \\
Equation & $\mathrm{Y}=119.9 \mathrm{x}+41.99$ \\
Range & $5-15 \mu \mathrm{gmL}^{-1}$ \\
\hline
\end{tabular}

\section{Precision}

The developed method has shown \%RSD less than 1.5 for peak area and retention time of curcumin for both intra-day and inter-day precision study, which ensures precision of the developed method.
The results of intra-day and inter-day precision study are summarized in table 3 and table 4.

Acceptance criteria: The \%RSD for retention time and peak area should be NMT 2.0 .

\section{Limit of detection and limit of quantification}

Limit of detection (LOD) and limit of quantitation (LOQ) was estimated from the standard deviation of the response and slope method. The LOD and LOQ were found to be 0.018 and $0.056 \mu \mathrm{g} / \mathrm{ml}$ for curcumin. This showed that the developed method can detect and quantify at lower concentration was highly sensitive whereas other methods are less sensitive $[5,10]$.

\section{Accuracy}

The percentage recovery of the spiked curcumin was within $100 \pm 2 \%$ which ensures the accuracy of the developed method. The results of recovery studies were summarized in table 5.

Acceptance criteria: Percent recovery should be between 98-102\%.

Table 3: Intra-day precision of the developed method

\begin{tabular}{|c|c|c|c|c|c|c|}
\hline \multirow[t]{3}{*}{ S. No. } & \multicolumn{6}{|c|}{ Curcumin concentration $(\mu \mathrm{g} / \mathrm{ml})$} \\
\hline & \multicolumn{2}{|c|}{5} & \multicolumn{2}{|l|}{10} & \multicolumn{2}{|l|}{15} \\
\hline & Area (mAU*sec) & $\mathrm{RT}^{*}$ (min) & Area (mAU*sec) & $\mathrm{RT}^{*}$ (min) & Area (mAU*sec) & $\mathrm{RT}^{*}(\mathrm{~min})$ \\
\hline 1. & 618.4 & 16.132 & 1268 & 16.052 & 1763 & 16.25 \\
\hline 2. & 614.5 & 16.145 & 1228 & 16.07 & 1762 & 16.24 \\
\hline 3. & 618.6 & 16.119 & 1241 & 16.05 & 1780 & 16.22 \\
\hline 4. & 617.1 & 16.052 & 1228 & 16.105 & 1766 & 16.20 \\
\hline 5. & 608.9 & 16.105 & 1252.2 & 16.145 & 1782 & 16.23 \\
\hline 6. & 618.2 & 16.132 & 1241 & 16.19 & 1780 & 16.27 \\
\hline Mean & 615.95 & 16.114 & 1243.03 & 16.102 & 1771.5 & 16.235 \\
\hline$\%$ RSD & 0.612 & 0.20 & 1.22 & 0.34 & 0.56 & 0.14 \\
\hline
\end{tabular}

*RT-Retention time

Table 4: Inter-day precision of the developed methods

\begin{tabular}{|c|c|c|c|c|c|c|}
\hline \multirow[t]{3}{*}{ S. No. } & \multicolumn{6}{|c|}{ Curcumin concentration $(\mu \mathrm{g} / \mathrm{ml})$} \\
\hline & \multicolumn{2}{|c|}{5} & \multicolumn{2}{|l|}{10} & \multicolumn{2}{|l|}{15} \\
\hline & Area (mAU*sec) & $\mathrm{RT}^{*}$ (min) & Area (mAU*sec) & $\mathrm{RT}^{*}$ (min) & Area (mAU*sec) & RT* (min) $^{*}$ \\
\hline 1. & 678.3 & 16.119 & 1276.2 & 16.145 & 1754.9 & 16.199 \\
\hline 2. & 669.2 & 16.119 & 1253 & 16.172 & 1784 & 16.279 \\
\hline 3. & 665.5 & 16.079 & 1230 & 16.132 & 1763 & 16.212 \\
\hline Mean & 671 & 16.10 & 1253.06 & 16.14 & 1767.3 & 16.23 \\
\hline$\%$ RSD & 0.98 & 0.14 & 1.84 & 0.12 & 0.84 & 0.26 \\
\hline
\end{tabular}

*RT-Retention time

Table 5: Accuracy of the developed method

\begin{tabular}{|c|c|c|c|c|}
\hline Level in \% & Amount spiked $(\mu \mathrm{g})$ & Amount recovered $(\mu \mathrm{g})$ & $\%$ recovery & Mean \% recovery \\
\hline \multirow[t]{3}{*}{$50 \%$} & 5 & 4.91 & 98.2 & 99.4 \\
\hline & 5 & 5.04 & 100 & \\
\hline & 5 & 5.01 & 100 & \\
\hline \multirow[t]{3}{*}{$100 \%$} & 10 & 9.88 & 98.6 & 99.50 \\
\hline & 10 & 10.19 & 101.91 & \\
\hline & 10 & 9.78 & 97.8 & \\
\hline \multirow[t]{3}{*}{$150 \%$} & 15 & 15.34 & 102.36 & 99.75 \\
\hline & 15 & 14.67 & 97.8 & \\
\hline & 15 & 14.86 & 99.10 & \\
\hline
\end{tabular}


Application of validated method for assay of curcumin nanoparticulate formulation

Developed method was successfully implemented in the assay of curcumin nanoparticulate formulation. Assay of curcumin was found to be $98.7 \%$. The extracting solvent was same as the mobile phase which helped in the complete extraction of curcumin from the formulation. The results are summarized in table 6 .

Table 6: Assay of curcumin

\begin{tabular}{ll}
\hline Parameter & Curcumin results \\
\hline Amount recovered $(\mathrm{mg})$ & 0.78 \\
Assay $(\%)$ & 98.7 \\
\hline
\end{tabular}

\section{Forced degradation study}

The samples subjected to various forced degradation conditions showed well-separated chromatograms of pure curcumin as well as some degradation peaks at different retention time. Chromatogram of untreated sample (standard peak) of curcumin is shown in fig. 3.

For the acidic, neutral hydrolysis and thermal degradation, the peaks of curcumin were less degraded as the peak areas of curcumin were decreased by $4.79 \%, 7.89 \%$ and $5.29 \%$ respectively with the appearance of one degradation product peak eluted far from the retention time of curcumin peak in case of acidic hydrolysis (fig. 4-6).

For the base hydrolysis, oxidative and photo-degradation, the peaks of curcumin were partially degraded as the peak areas of curcumin were decreased by $23.86 \%, 23.24 \%$ and $22.66 \%$ respectively with the appearance of one degradation product peak eluted far from the retention time of curcumin peak in case of base hydrolysis and photodegradation (fig. 7-9). Curcumin was found to be highly degraded under alkaline conditions.

In order to develop a suitable RP-HPLC method for the estimation of curcumin, different buffer ratios at different flow rate were applied. The reported methods were costly due to the use of highly sophisticated instruments like mass spectrometry [16] and detectors like fluorescence detectors [10]. The use of expensive solvents such as tetrahydrofuran $[11,12]$ was replaced by acetonitrile in this study. The LOD and LOQ were found to be 0.018 and $0.056 \mu \mathrm{g} / \mathrm{ml}$, respectively, which indicates that the method was sensitive, and can detect and quantify at lower levels of curcumin. Linearity range was from $5-15 \mu \mathrm{g} / \mathrm{ml}$ for curcumin with regression coefficient 0.997 indicates that at this concentration range curcumin was highly linear. Percent assay of curcumin and amount of curcumin recovered was found to be $98.7 \%$ and $0.78 \mathrm{mg}$ respectively. The developed RP-HPLC stability indicating assay method was found to be appropriate for the analysis of drug in their pure form and in the nanoparticulate formulation.

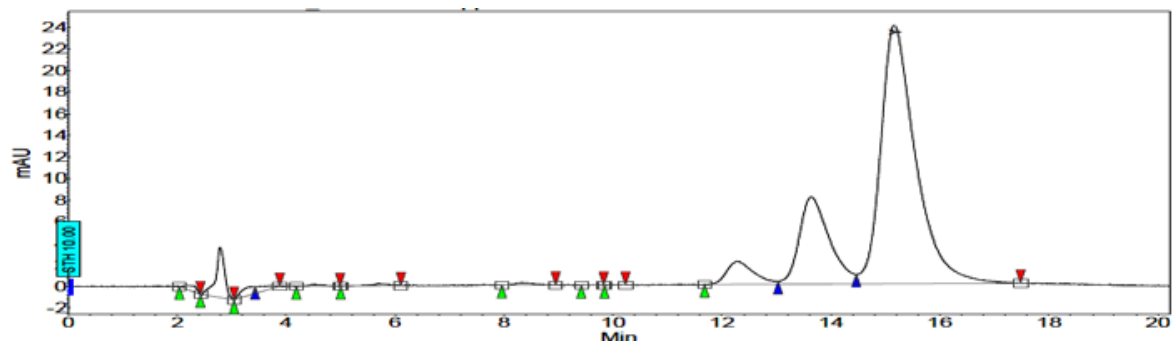

Fig. 3: Chromatogram of untreated sample of curcumin

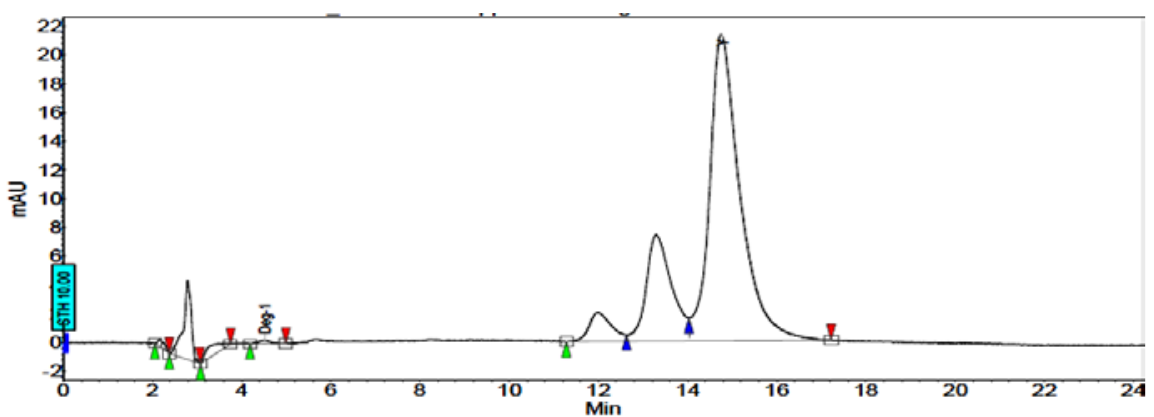

Fig. 4: Chromatogram of acid hydrolysis

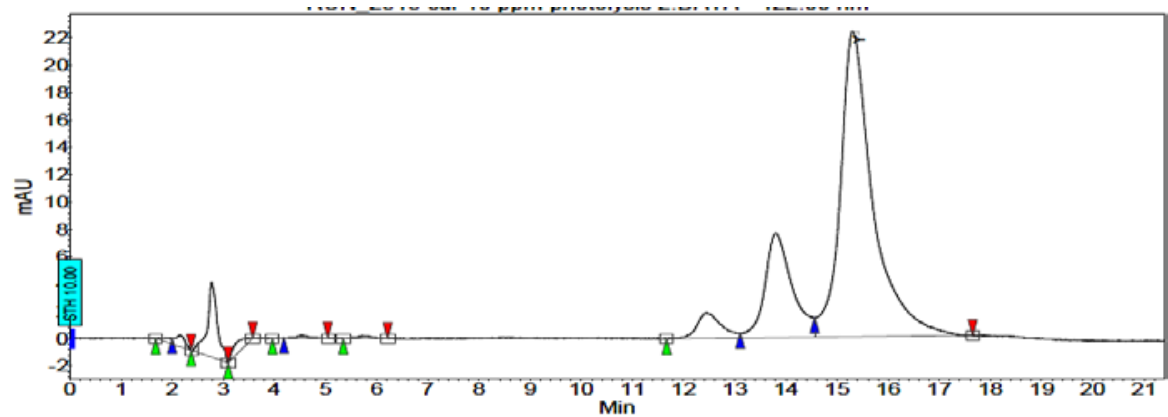

Fig. 5: Chromatogram of neutral hydrolysis 


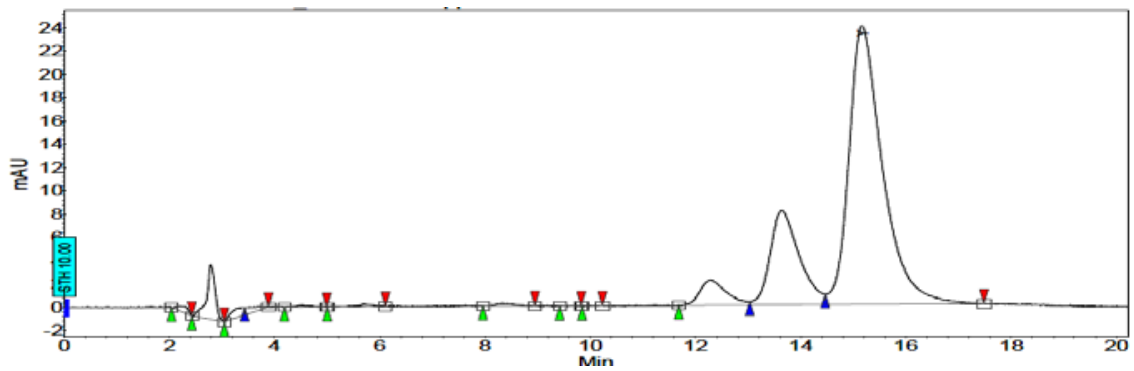

Fig. 6: Chromatogram of thermal degradation

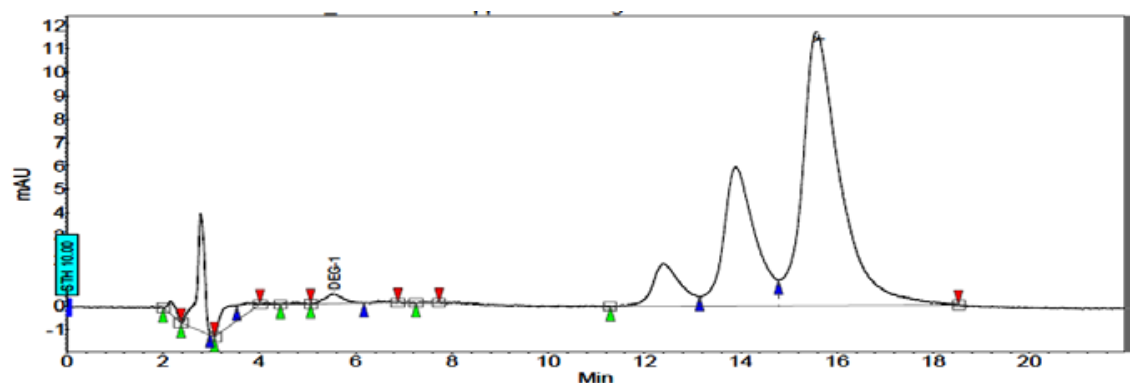

Fig. 7: Chromatogram of base hydrolysis

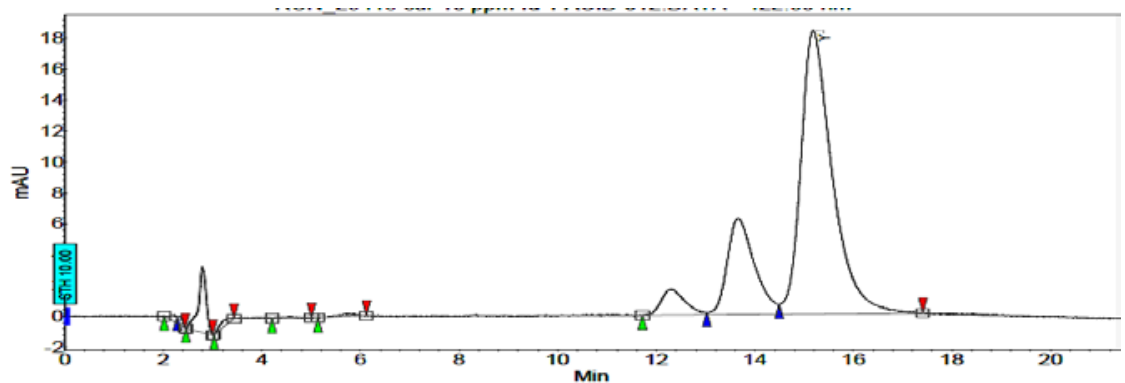

Fig. 8: Chromatogram of oxidative degradation

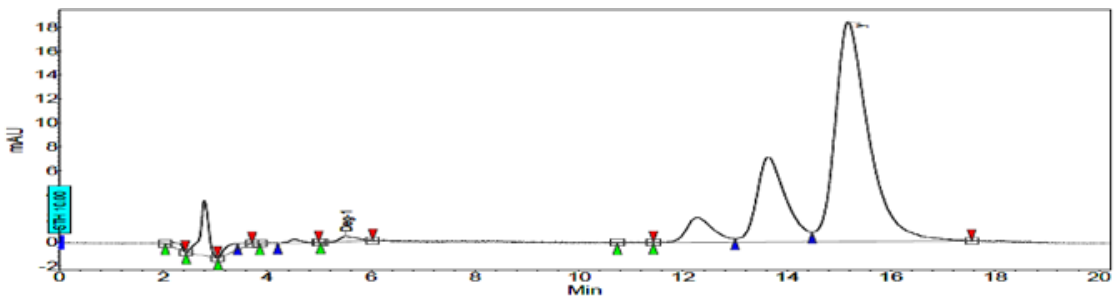

Fig. 9: Chromatogram of photo-degradation

\section{CONCLUSION}

A simple, cost-effective and stability-indicating isocratic reversed phase HPLC method has been developed for the determination of curcumin in bulk drug substance and dosage form. The developed method was validated as per ICH guideline and statistical analysis also proves that the method is linear, precise, accurate and specific for the analysis of curcumin. The developed method was successfully implemented in the assay of curcumin nanoparticulate formulations. Thus, developed method can be used for routine analysis of curcumin in pharmaceutical dosage forms.

\section{ACKNOWLEDGEMENT}

Authors are thankful to All India Council for Technical Education, New Delhi for supporting this work (Ref. no (REF NO: 8159/RIFD/RPS/Policy-4/2013-14) and VAV life Sciences Pvt. Ltd for gift sample of Curcumin.

\section{CONFLICTS OF INTERESTS}

Declared none

\section{REFERENCES}

1. Korany MA, Haggag RS, Ragab MA, Elmallah OA. A validated stability-indicating HPLC method for simultaneous determination of silymarin and curcumin in various dosage forms. Arabian J Chem 2013;6:1-15.

2. Gugulothu DB, Patravale VB. A new stability-indicating HPLC method for simultaneous determination of curcumin and celecoxib at single wavelength: an application to the nanoparticulate formulation. Pharm Anal Acta 2012;3:1-6.

3. Sarvesh S, Gaurav KS, Vimal K. Development of spectrophotometric methods for simultaneous determination of artesunate and curcumin in a liposomal formulation. Int J Appl Pharm 2015;7:18-21. 
4. Radhika G, Manoj KS, Gulab ST, Avinash S. Study of formulation characterization and wound healing potential of transdermal patches of curcumin. Asian J Pharm Clin Res 2012;5:225-30.

5. Steffi PF, Srinivasan M. Curcumin, a potent anticarcinogenic polyphenol-a review. Asian J Pharm Clin Res 2014;7:1-8.

6. FDA Professional Drug Information Home Page. Available from: http://www.drugs.com. [Last accessed on 30 Mar 2015].

7. Basnet $\mathrm{P}$, Basnet NS. Review curcumin: an anti-inflammatory molecule from a curry spice on the path to cancer treatment. Mol 2011;16:4567-98.

8. Ansari MJ, Ahmad S, Kohli K, Ali J, Khar RK. Stability-indicating HPTLC determination of curcumin in bulk drug and pharmaceutical formulations. J Pharm Biomed Anal 2005;39:132-8.

9. Lechtenberg $\mathrm{M}$, Quandt B, Nahrstedt A. Quantitative determination of curcuminoids in curcuma rhizomes and rapid differentiation of curcuma domestica val. and curcuma xanthorrhiza roxb. by capillary electrophoresis. Phytochem Anal 2004;15:152-8.

10. Schiborr C, Eckert GP, Rimbach G, Frank J. A validated method for the quantification of curcumin in plasma and brain tissue by fast narrow-bore high-performance liquid chromatography with fluorescence detection. Anal Bioanal Chem 2010;397:1917-25.

11. Han YR, Zhu JJ, Wang YR, Wang XS, Liao YH. A simple RP-HPLC method for the simultaneous determination of curcumin and its prodrug, curcumin di-decanoate, in rat plasma and the application to pharmacokinetic study. Biomed Chromatogr 2011;25:1144-9.
12. Yadav VR, Sarasija S. A sensitive reversed-phase HPLC method for the determination of curcumin. Pharmacogn Mag 2009;5:71-4.

13. Moorthi C, Kathiresan K. Simultaneous estimation of curcumin and piperine using validated RP-HPLC-PDA method and its application in pharmaceutical nanoformulation. Int J Pharm Pharm Sci 2013;5:475-8.

14. Dandekar PP, Patravale VB. Development and validation of a stability-indicating LC method for curcumin. Chromatographia 2009;69:871-7.

15. Wang F, Hung W, Wang Y. Fluorescence enhancement effect for the determination of curcumin with yttrium(III)-curcuminsodium dodecyl benzene sulfonate system. J Lumin 2008;128:110-6.

16. Goren AC, Cikrikci S, Cergel M, Bilsel G. Rapid quantitation of curcumin in turmeric via NMR and LC-tandem mass spectrometry. J Food Chem 2009;113:1239-42.

17. Zhao $\mathrm{XL}$, Yang $\mathrm{CR}$, Yang $\mathrm{KL}$, Li $\mathrm{KX}$, Yang $\mathrm{HH}$, Chen WD. Preparation and characterization of nanostructured lipid carriers loaded traditional chinese medicine, zedoary turmeric oil. Drug Dev Ind Pharm 2010;36:773-80.

18. ICH guidance on method validation; validation of analytical procedures text and methodology Q2; 2005.

\section{How to cite this article}

- Suchitra Panigrahi, Rajashree Hirlekar. A new stabilityindicating RP-HPLC method for determination of curcumin: an application to the nanoparticulate formulation. Int J Pharm Pharm Sci 2016;8(12):149-155. 